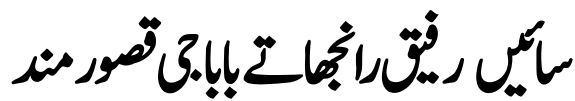

\section{Sain Rafiq Ranjha and Baba Qasoor Mand}

Akbar Ali Ghazi

Lecturer, Department of Punjabi, Graduate College, Daska, Sialkot.

\section{KEYWORDS}

Sufi Poet

Research

Poetic Contributions

Poetry Collections

Baba Qasoor Mand

\section{DATES}

\begin{tabular}{ll}
\hline Received & $19-10-2021$ \\
Accepted & $05-12-2021$ \\
Published & $21-12-2021$ \\
QR CODE & \\
\hline
\end{tabular}

\section{ABSTRACT}

This article covers the poetic and research services of Sufi poet Sain Muhammad Rafique Ranjha from Hamza Ghous Sialkot. He is a Punjabi "Sofi "poet and a compiler. In this article, I have already mentioned his own poetry collection and life. In his own book, he has used a dozen genres of poetry. This Sufi poet, who is experimenting with new and old genres, but "Rubai" is his favorite genre. The first book "Warasat-e-Faqr" by Sain Muhammad Rafique Ranja consists of 418 pages which has been composed. While the second book "Suchay Moti" is by the famous Punjabi poet of Gujarat Baba Ji Qasoor Mandwhich has 290 pages. It is published in 2017. Both books contain mystical poetry. Along with the books, brief information about the lives of the authors is also given.

\section{DOI: https://doi.org/10.54064/negotiations.v1i3.30}

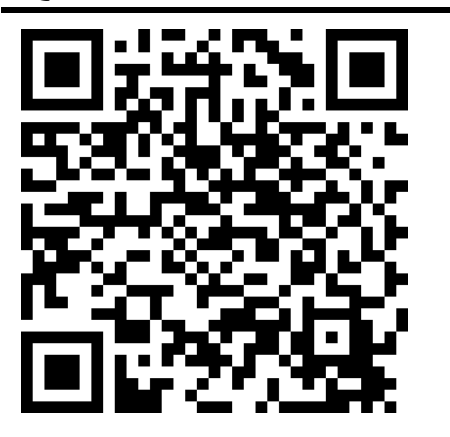

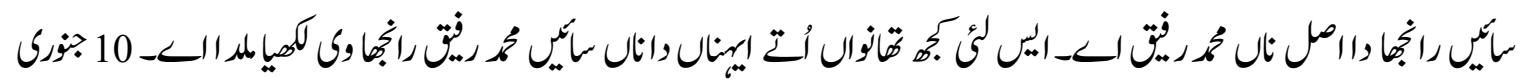

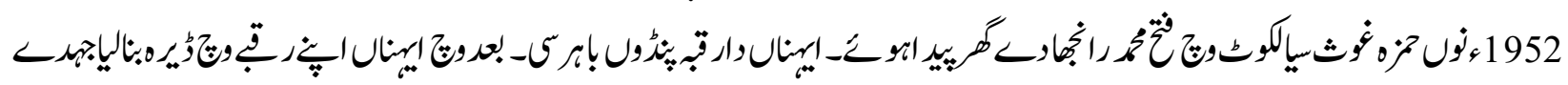

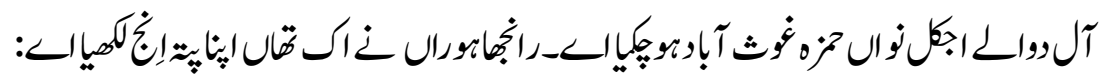

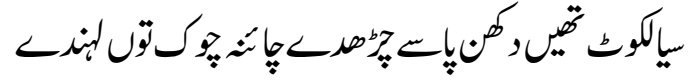

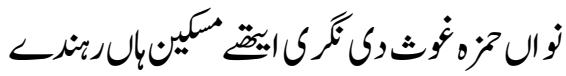

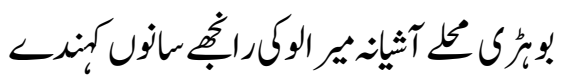




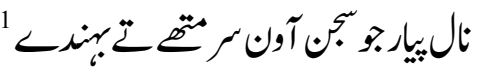

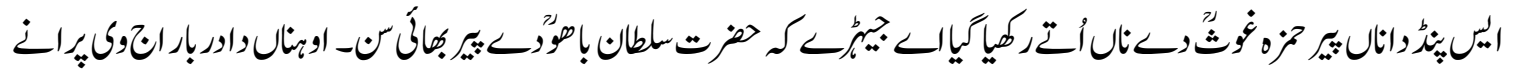

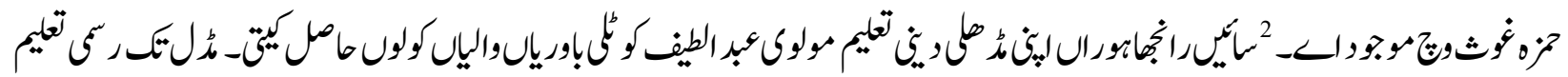

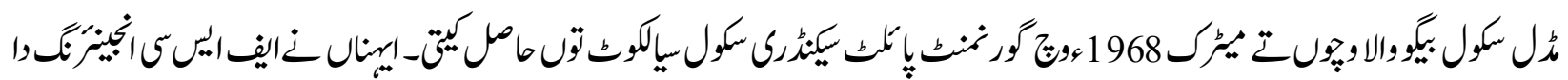

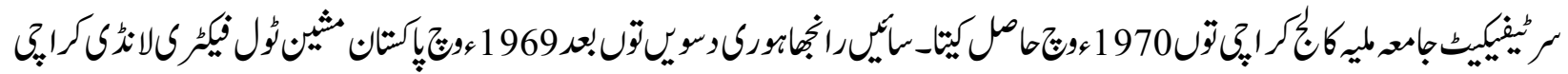

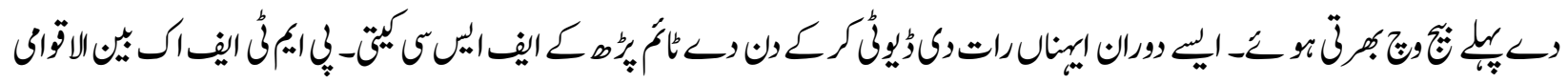

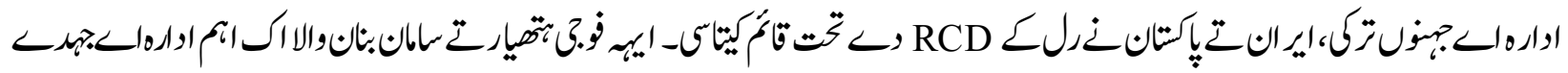

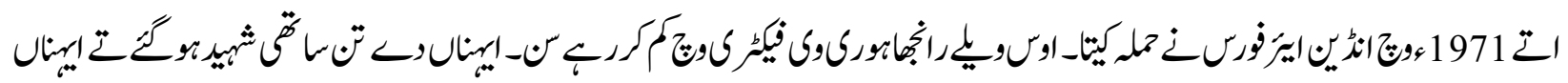

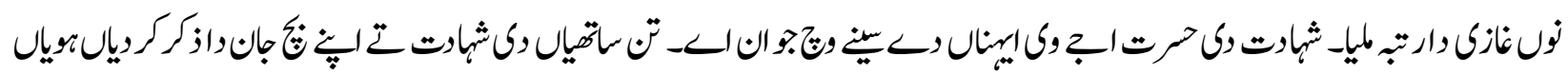

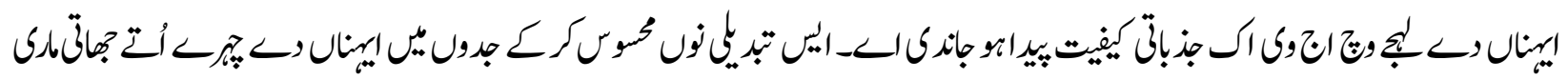

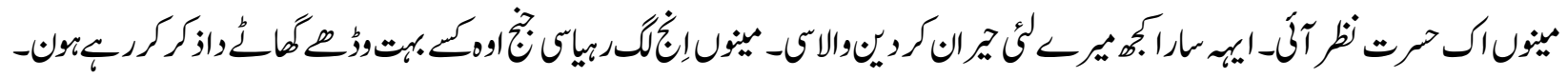

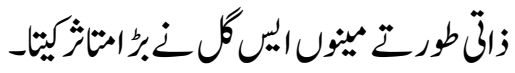

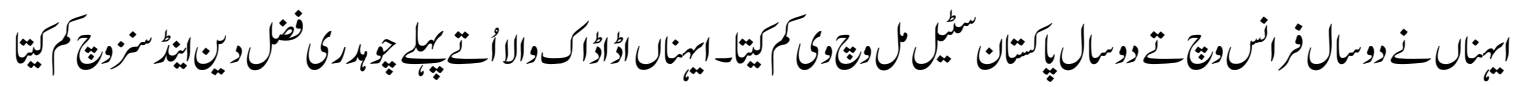

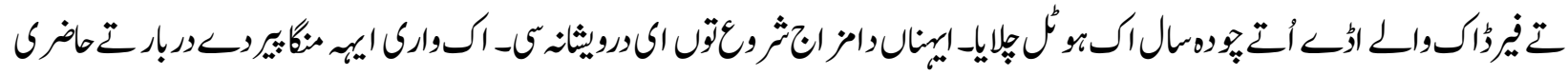

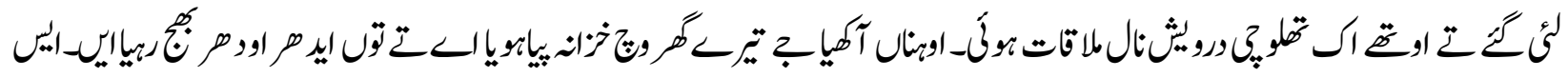

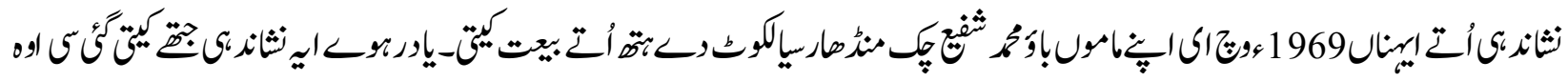

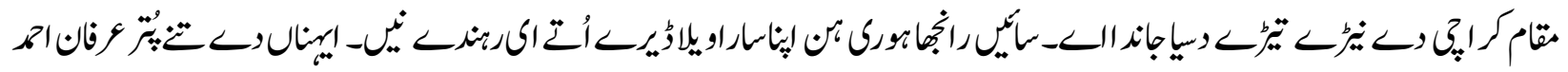

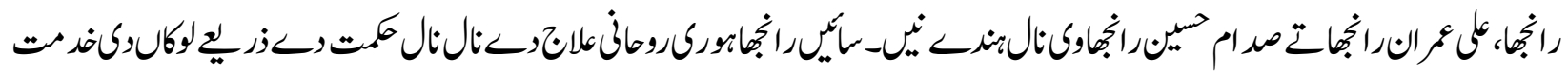

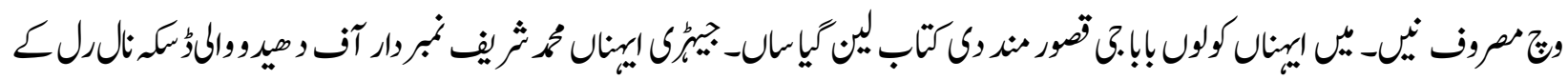

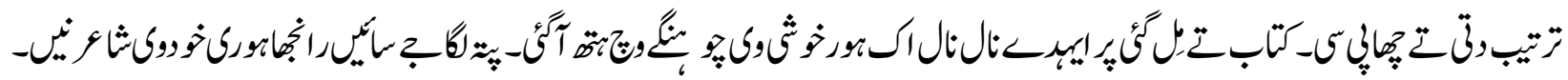

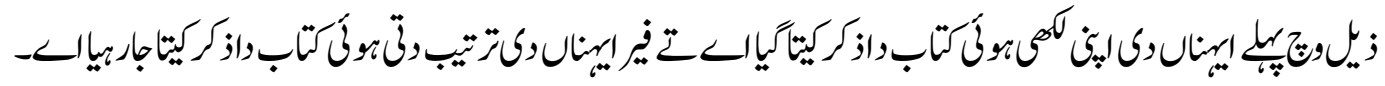
1 وراثت فنق، قنى:

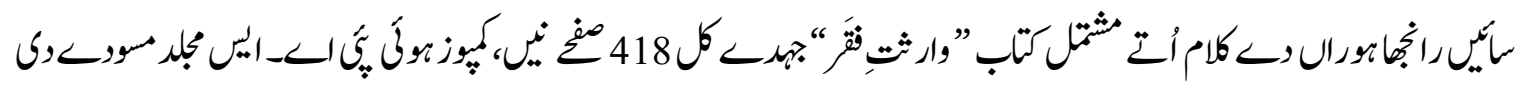

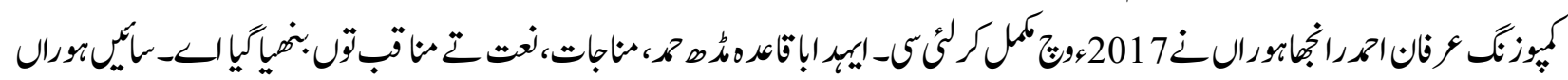

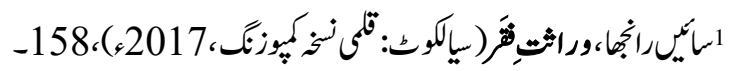

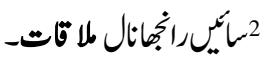




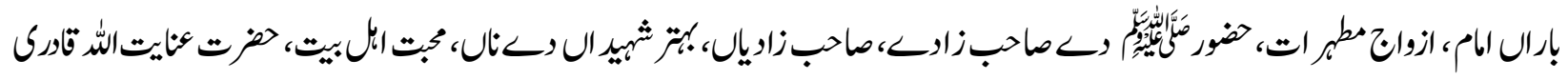

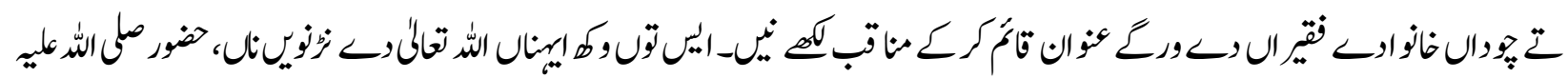

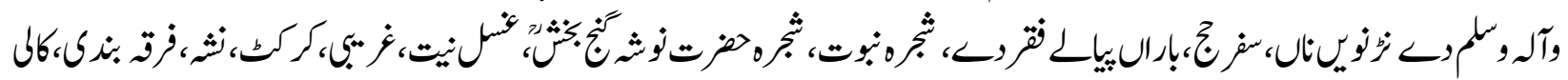

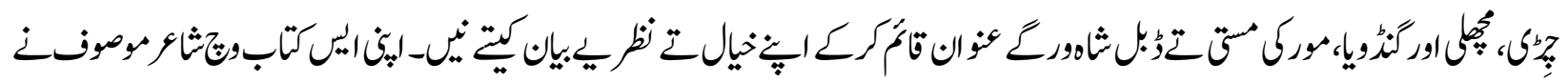

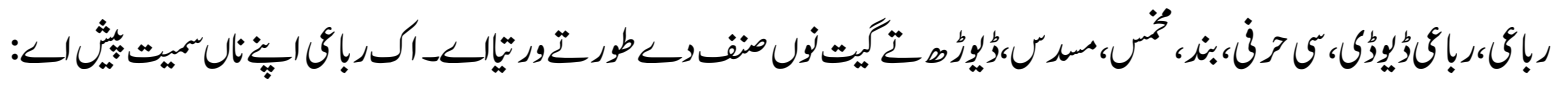

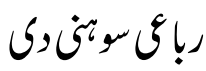

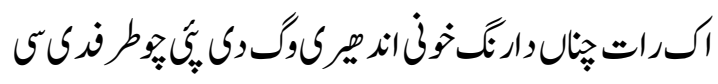

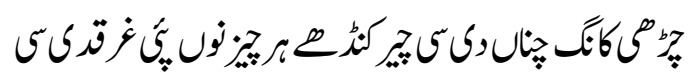

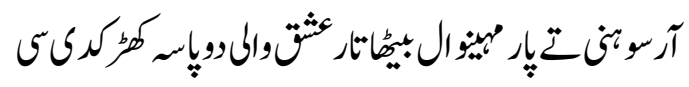

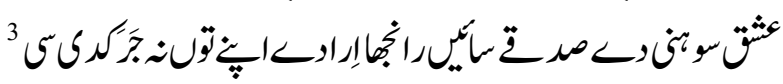

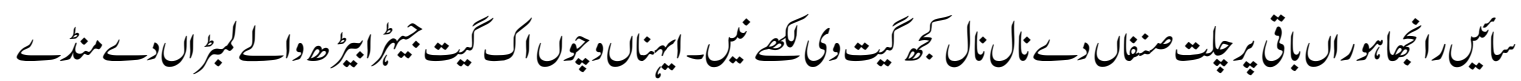

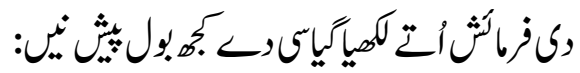

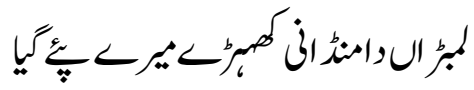

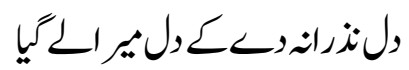

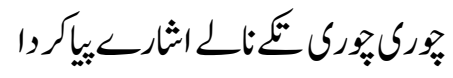

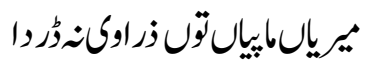

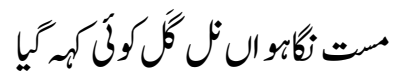

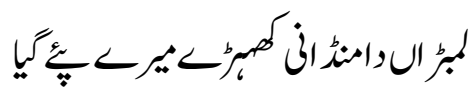

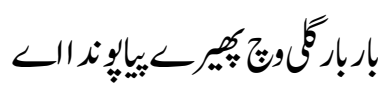

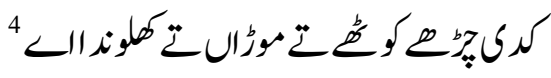

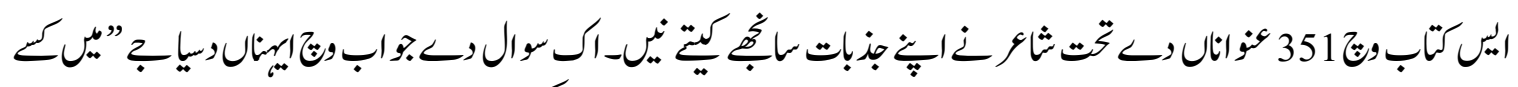

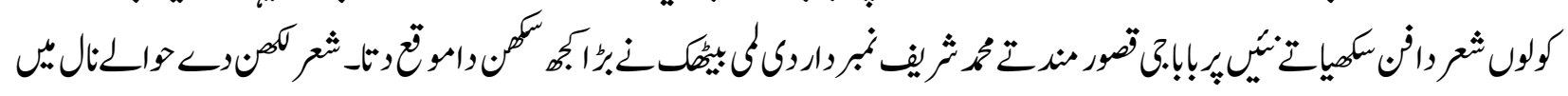

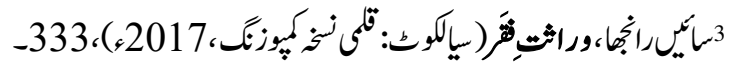




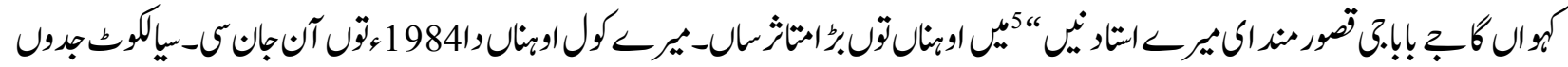

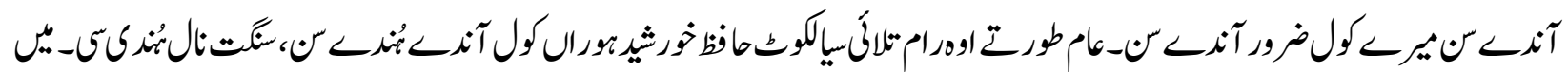

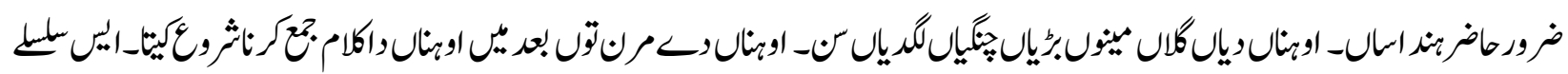

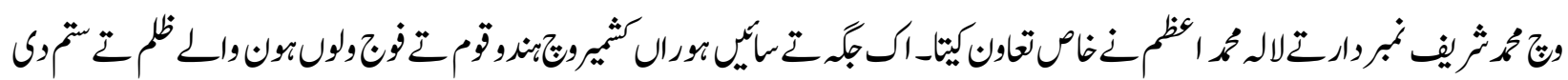

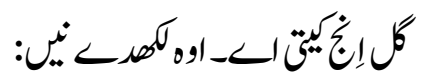

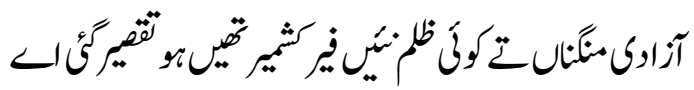

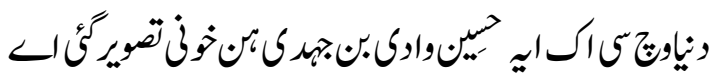

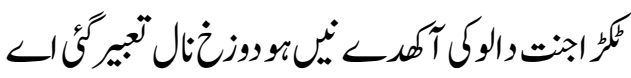

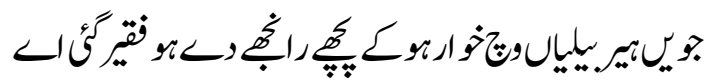

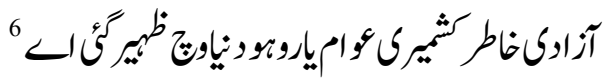
2-

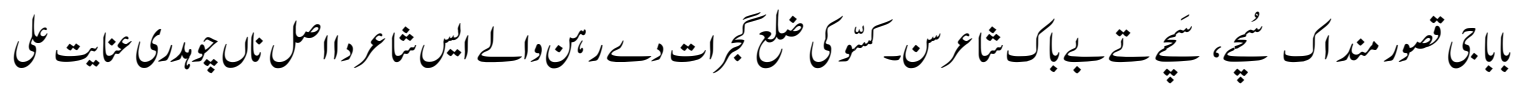

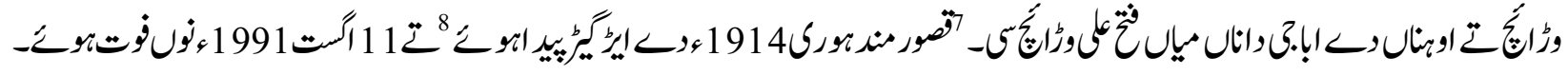

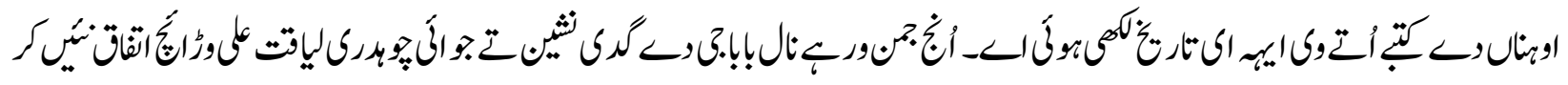

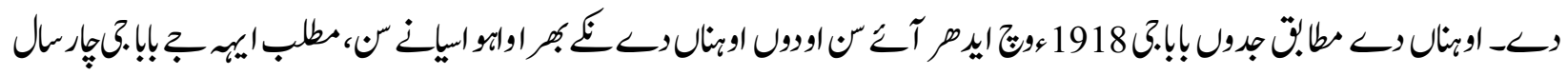

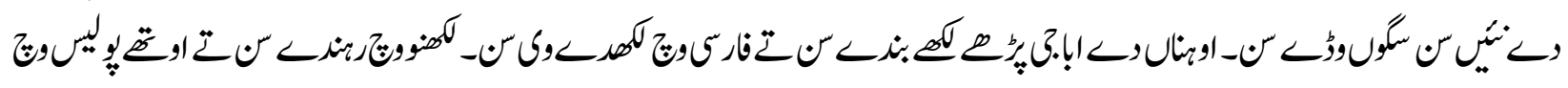

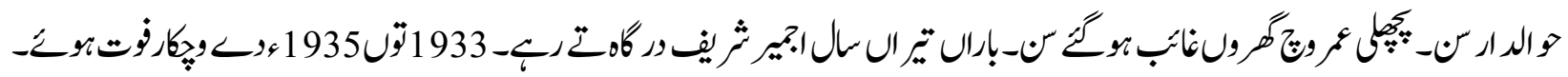

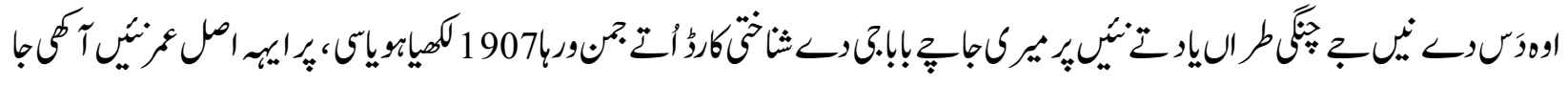

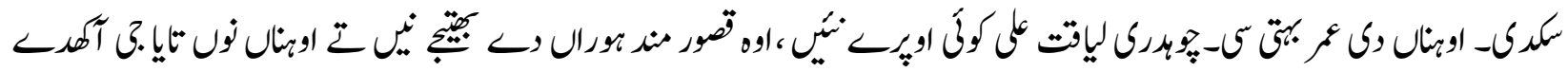

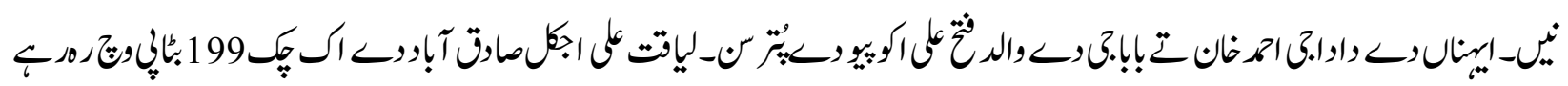

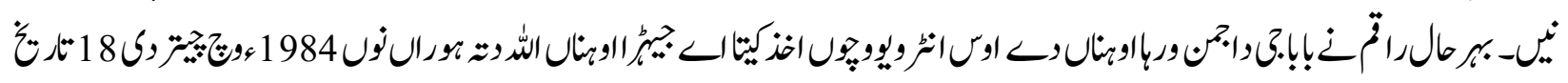

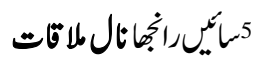

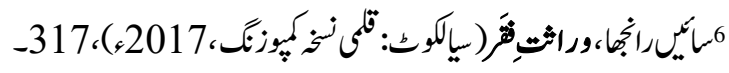

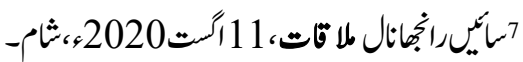

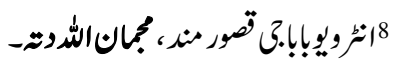




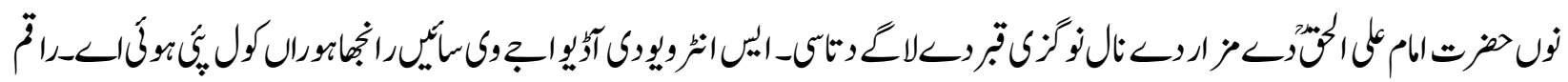

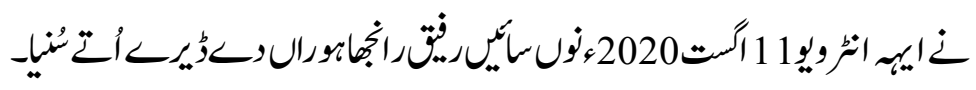

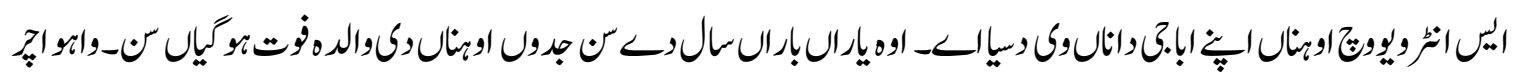

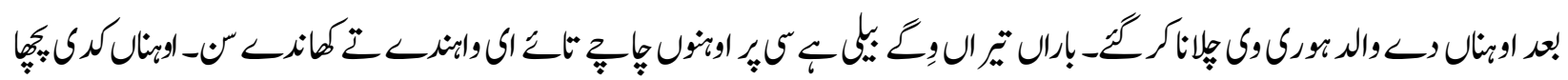

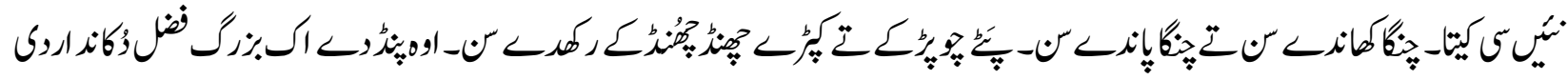

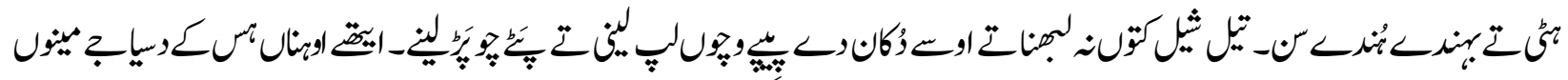

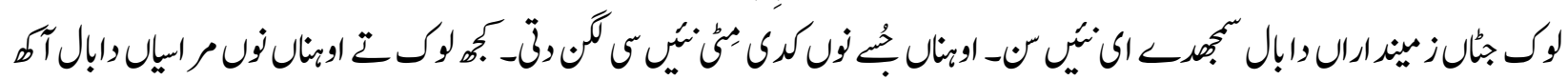

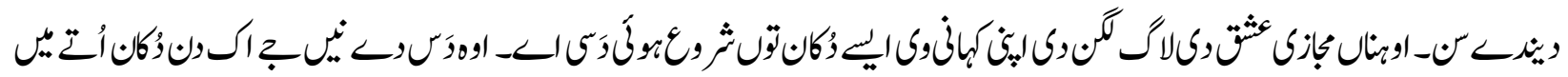

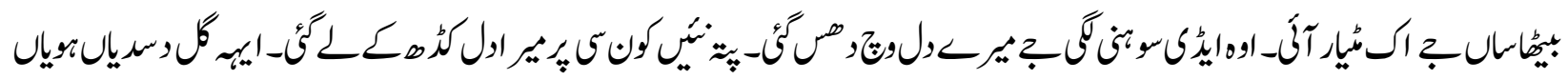

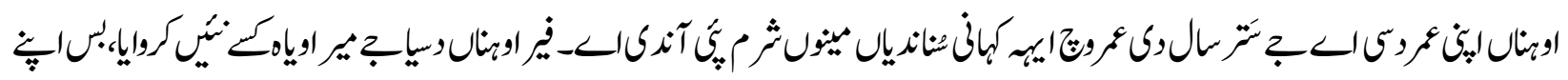

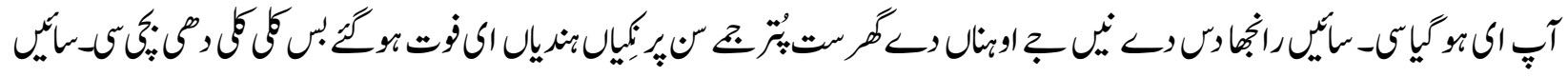

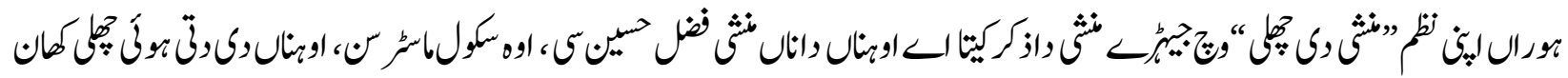

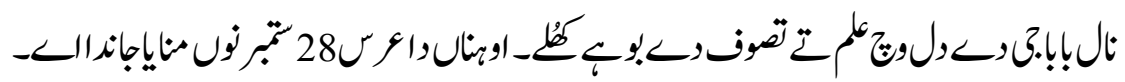

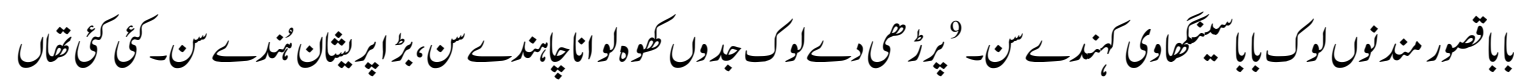

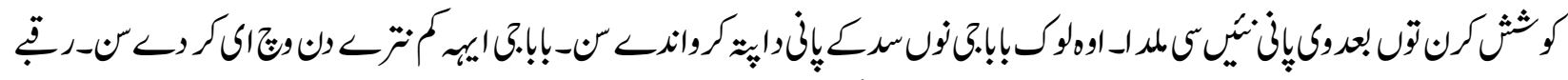

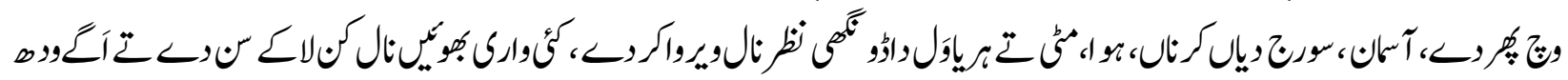

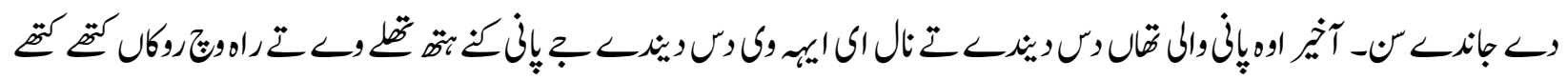

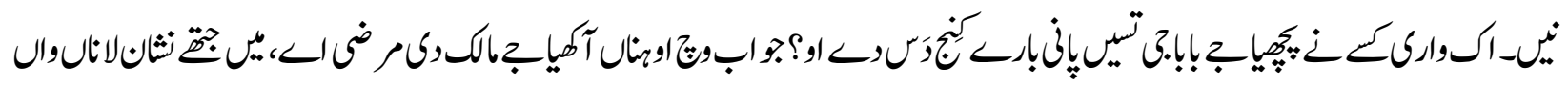

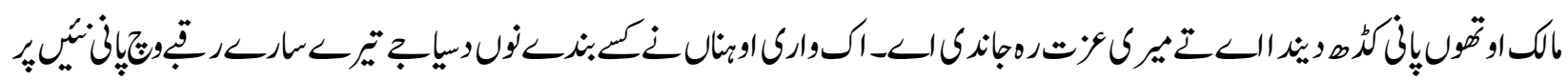

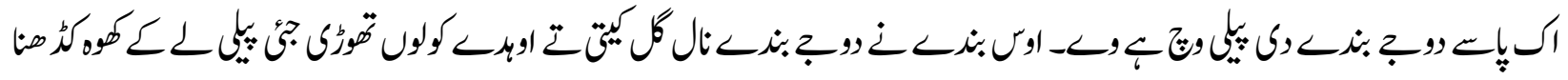

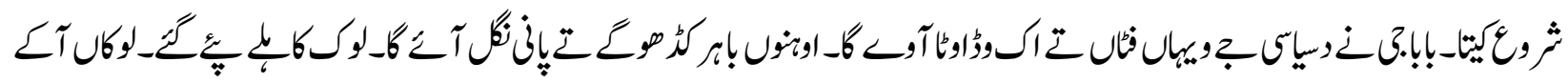

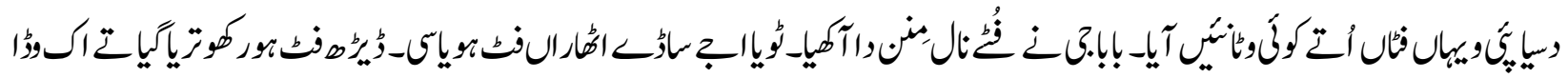

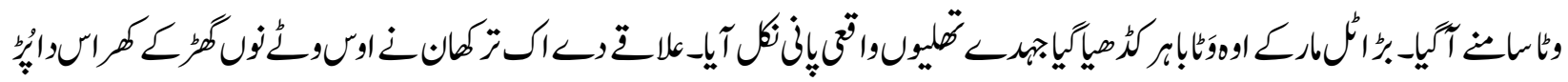

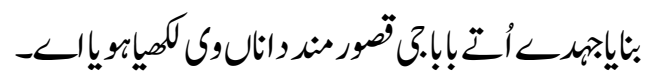

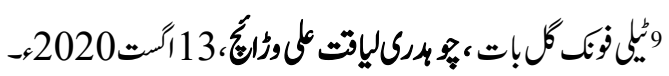




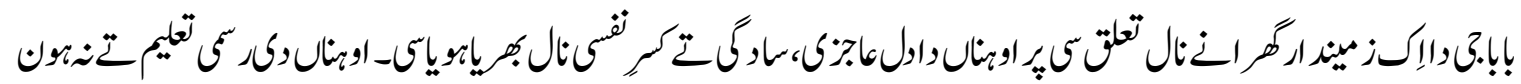

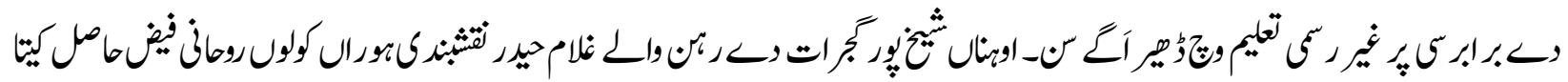

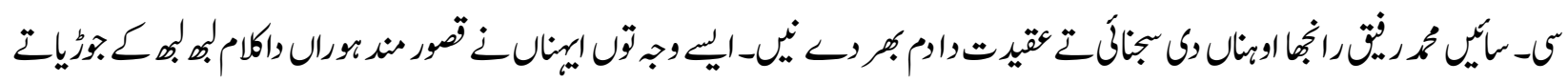

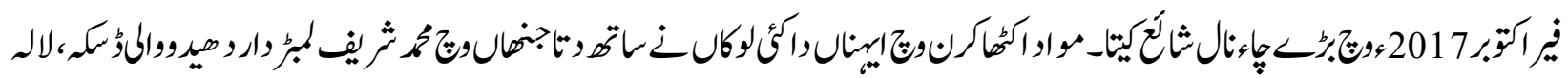

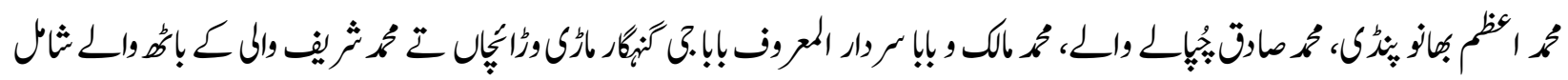

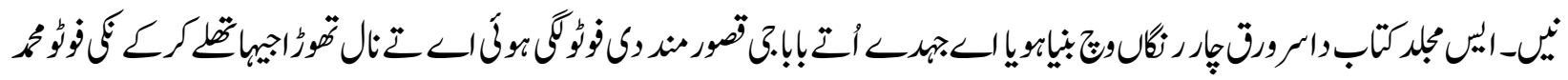

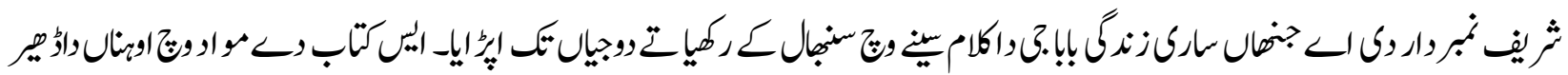

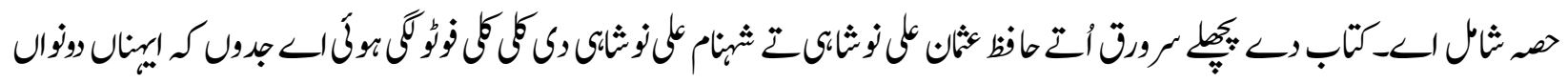

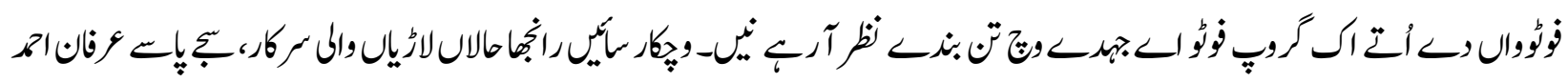

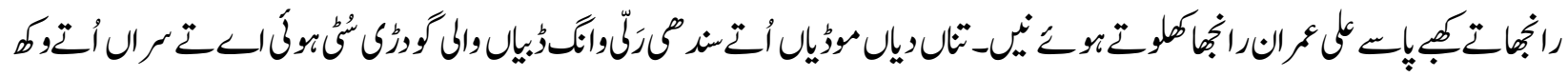

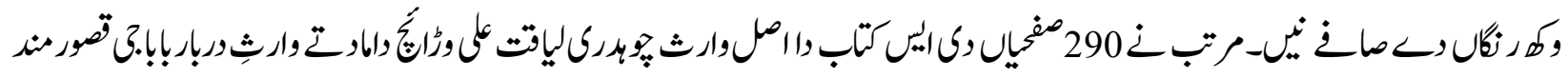

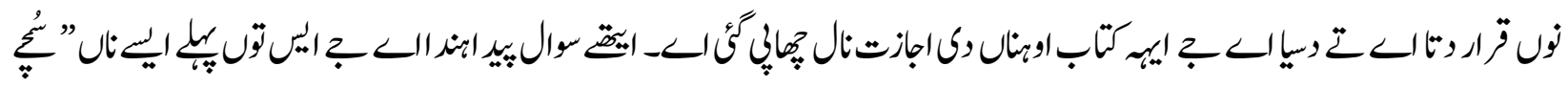

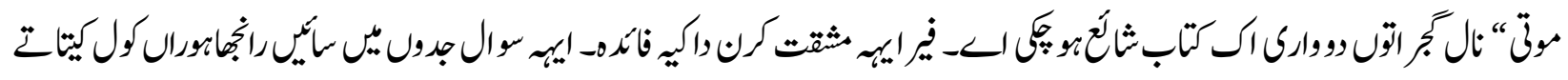

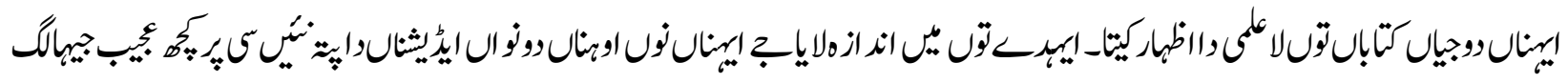

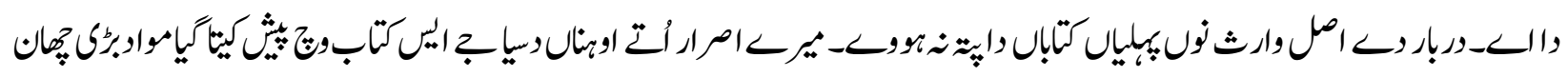

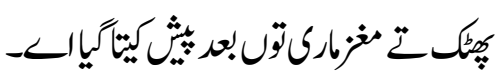

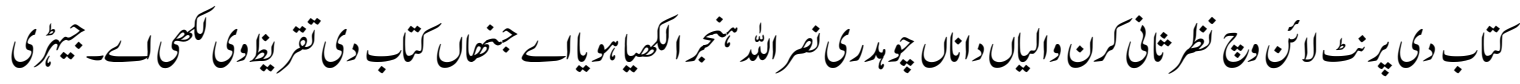

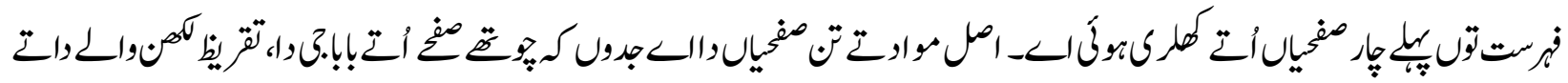

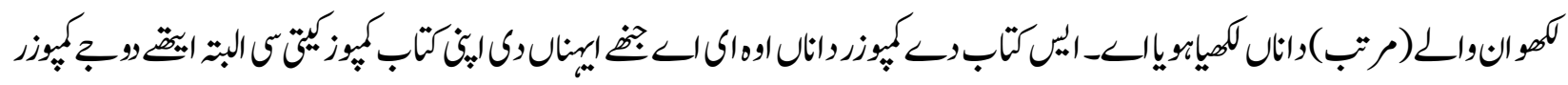

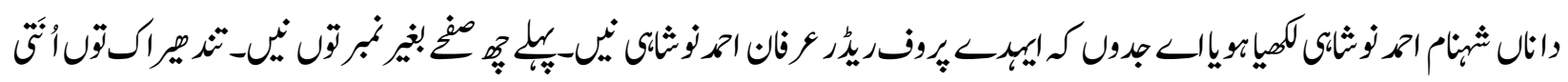

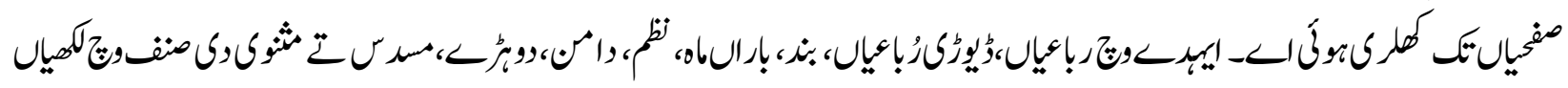

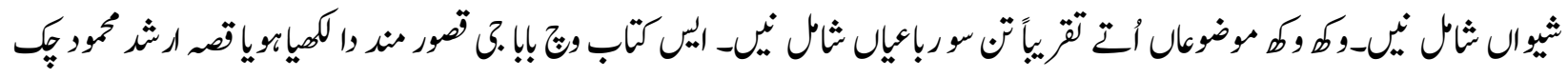

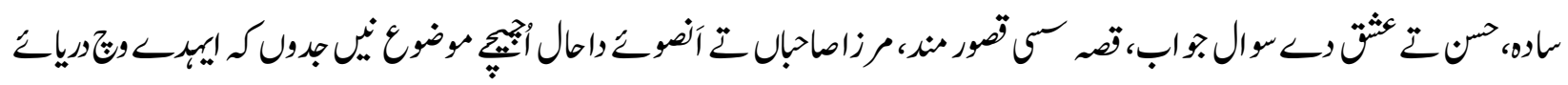

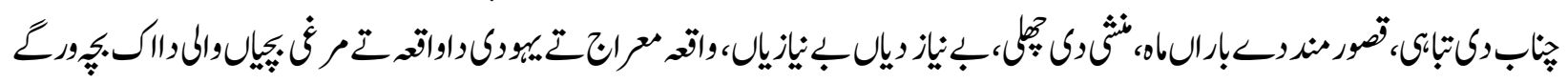

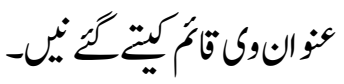

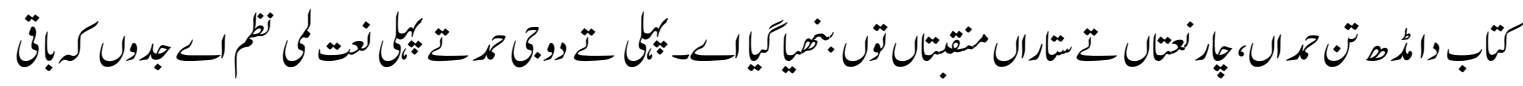

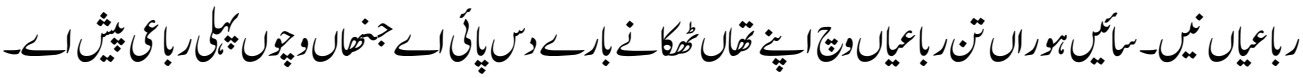




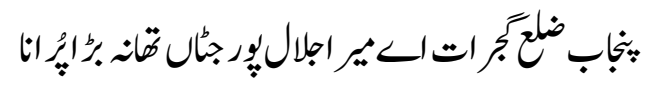

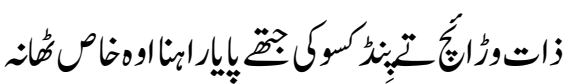

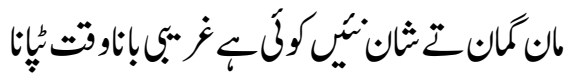

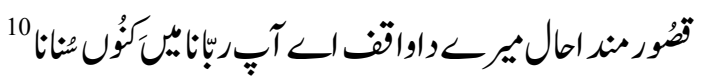

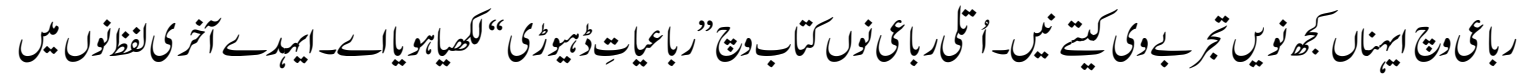

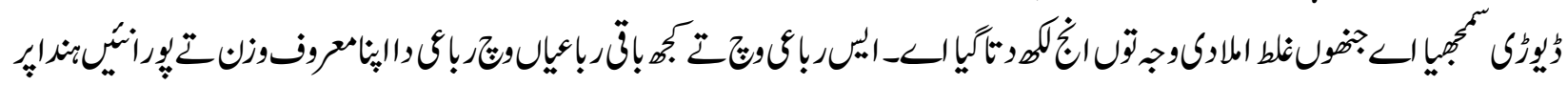

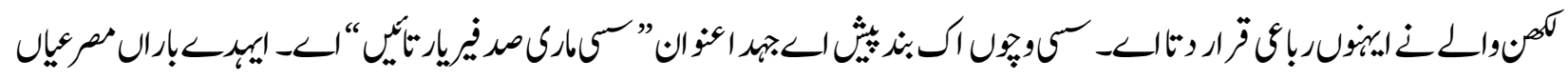

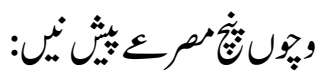

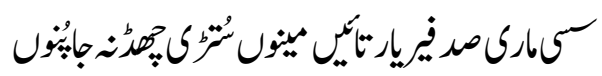

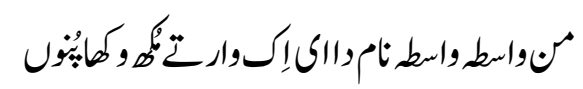

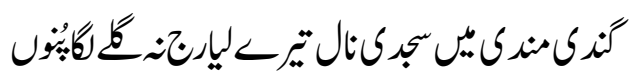

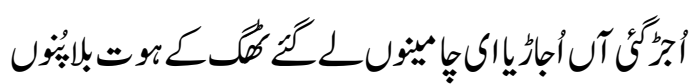

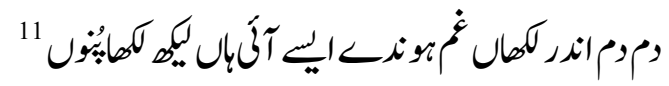

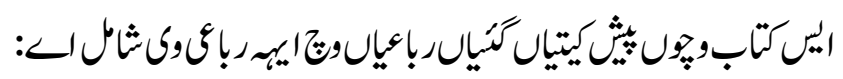

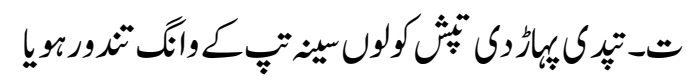

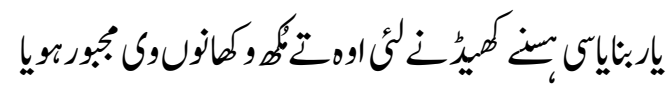

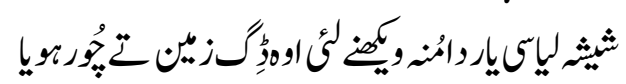

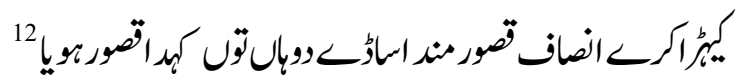

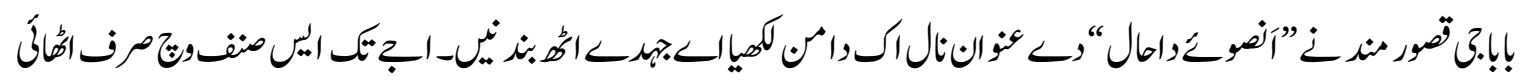

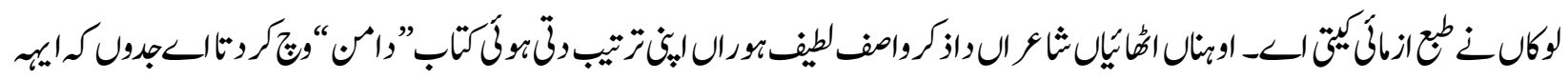

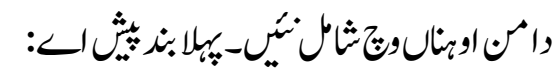

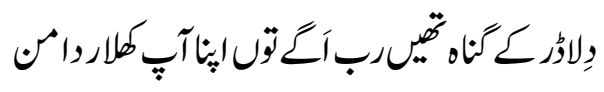

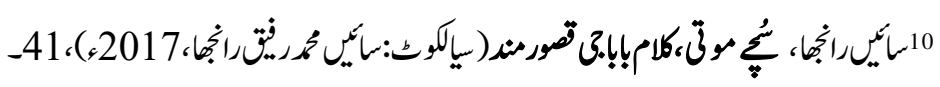
-130، 11 272 12 


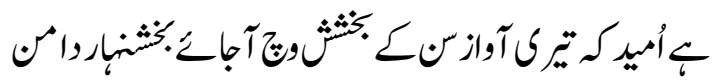

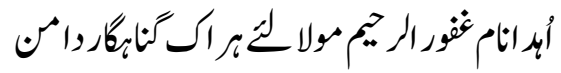

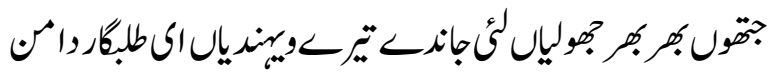

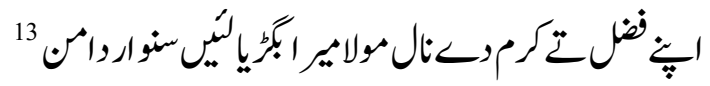

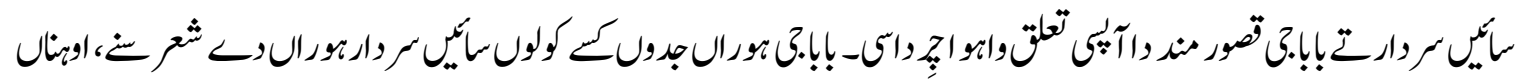

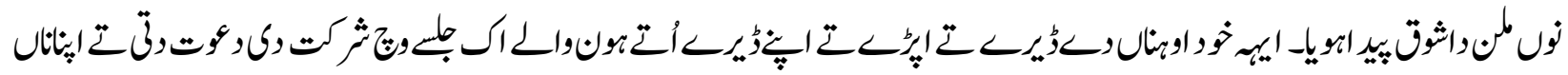

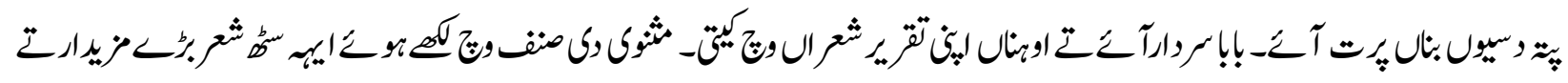

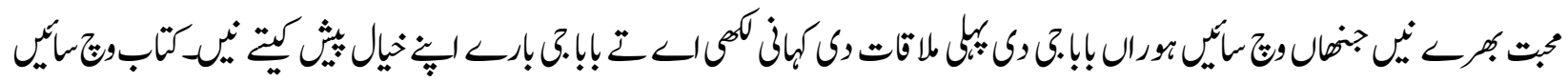

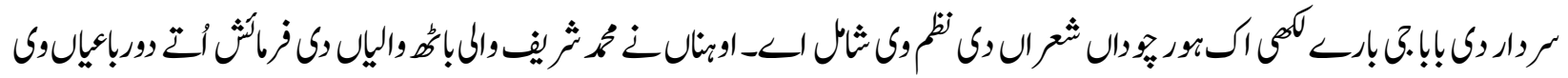

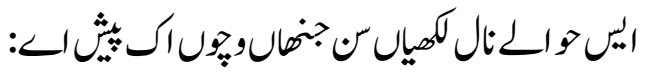

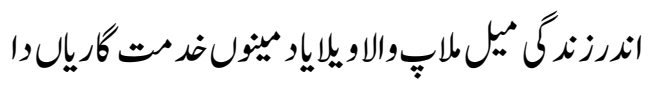

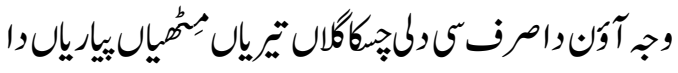

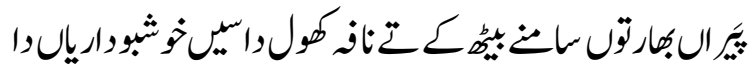

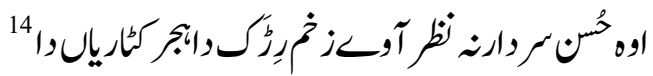

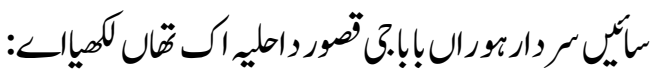

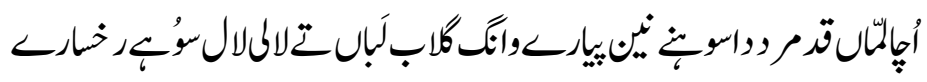

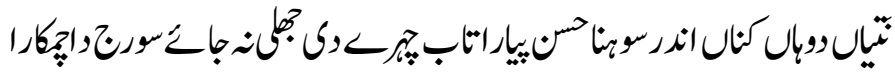

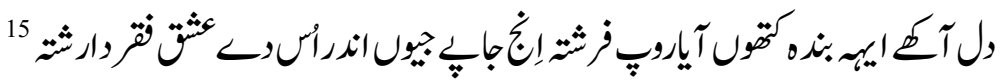

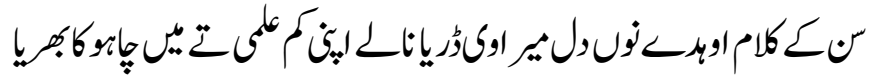

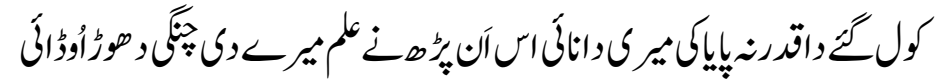

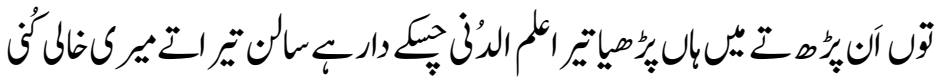

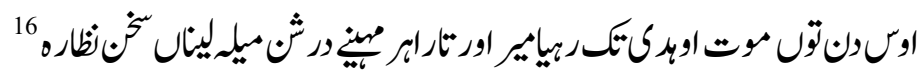




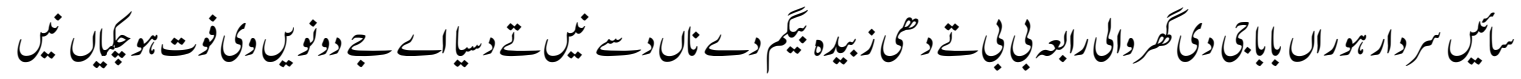

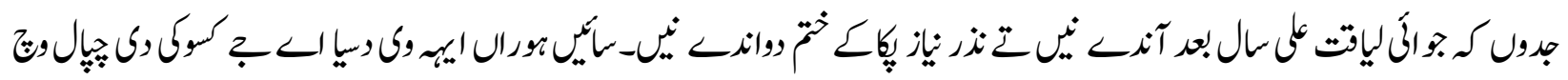

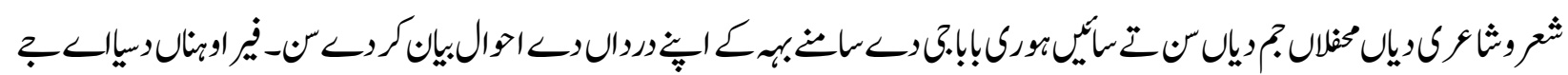

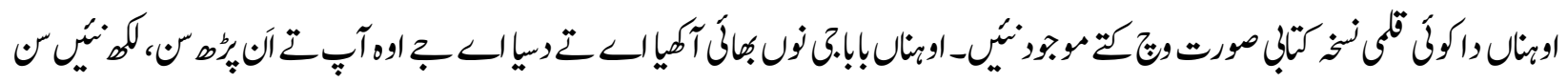

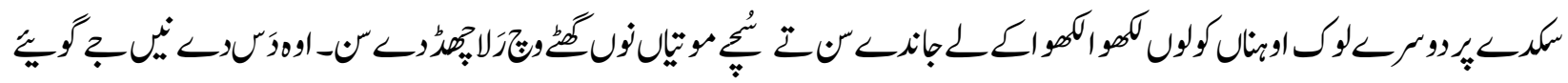

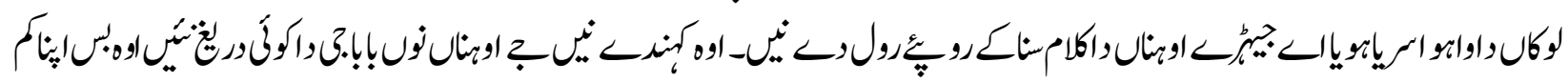

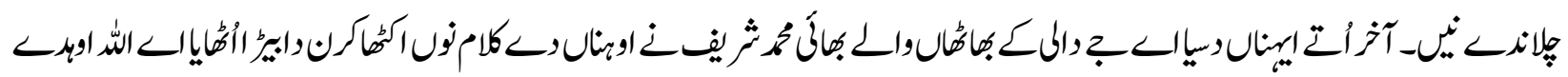

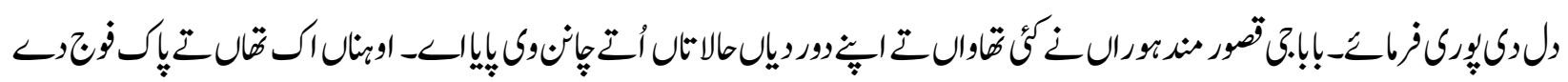

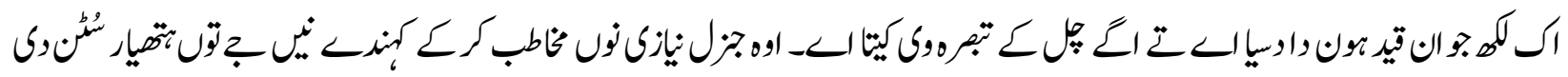

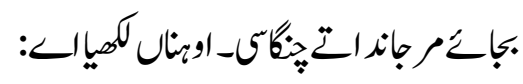

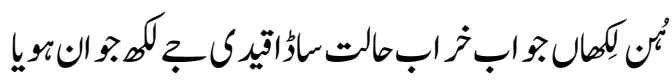

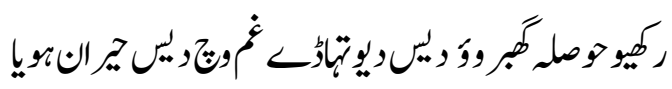

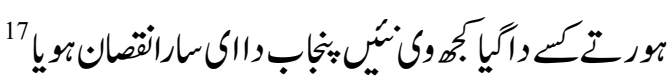

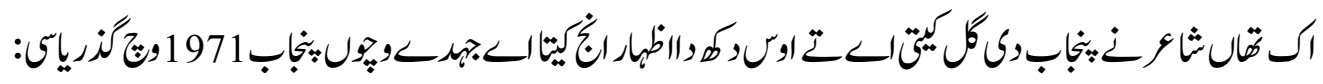

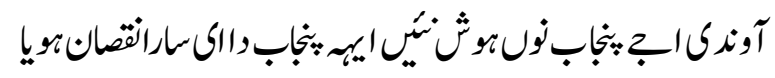

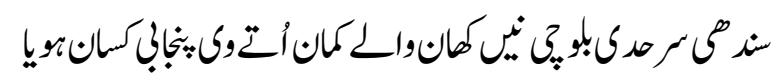
جزلئي

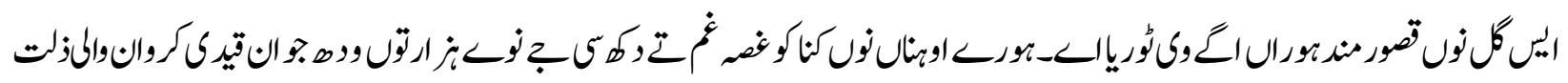

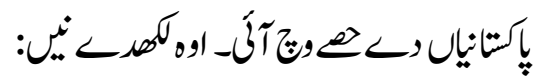

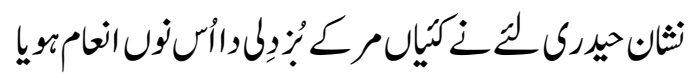

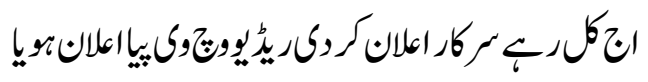

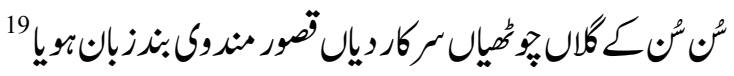




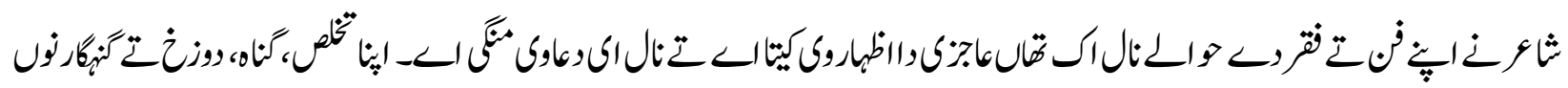

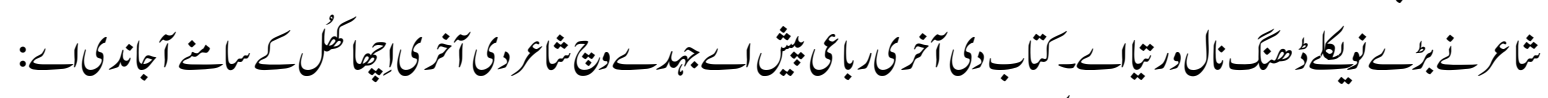

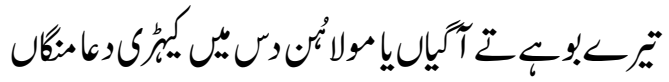

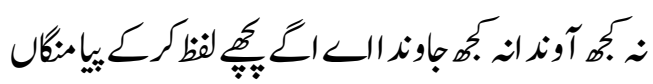

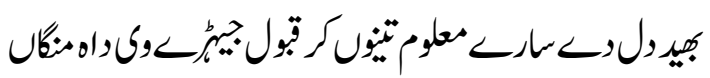

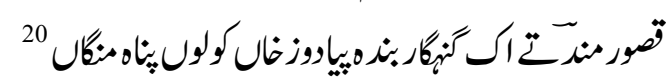

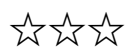

